\title{
Protocol for the Controlled evaLuation of Angiotensin Receptor blockers for COVID- 19 resplraTorY disease (CLARITY): a randomised controlled trial
}

Carinna Hockham ${ }^{1,2 \dagger}$, Sradha Kotwal ${ }^{1,3+}$, Arlen Wilcox ${ }^{1,4^{*}}$ (D), Abhinav Bassi ${ }^{5}$, James McGree ${ }^{6}$, Carol Pollock ${ }^{7,8}$, Louise M. Burrell ${ }^{9}$, Nikita Bathla ${ }^{5}$, Mallikarjuna Kunigari ${ }^{5}$, Vinay Rathore ${ }^{10}$, Michael John ${ }^{11}$, Enmoore Lin ${ }^{1}$, Christine Jenkins ${ }^{1,12}$, Angus Ritchie ${ }^{12}$, Andrew McLachlan ${ }^{12,13}$, Thomas Snelling ${ }^{14,15}$, Mark Jones ${ }^{14}$, Vivekanand $\mathrm{Jha}^{1,5+}$, Meg Jardine ${ }^{1,4+}$ on behalf of the CLARITY Investigators

\begin{abstract}
Background: SARS-CoV-2 binds to membrane-bound angiotensin-converting enzyme 2 (ACE2) which may result in downregulation of membrane-bound ACE2. ACE2 is a key regulator of the renin-angiotensin system (RAS) and is responsible for degrading angiotensin II and thereby counteracting its pro-inflammatory, pro-fibrotic effects mediated through the angiotensin II type 1 receptor (AT1R). As AT1R is directly blocked by angiotensin receptor blockers (ARBs), these agents may offer a safe, low-cost solution for reducing COVID-19 respiratory outcomes.

Methods and discussion: CLARITY is a pragmatic, adaptive, two-arm, multi-centre, comparative effectiveness phase III randomised controlled trial that examines whether ARBs reduce COVID-19 severity among high-risk patients. Recruiting in India and Australia, the trial will compare treatment with a maximum tolerated daily dose of an ARB to standard of care. Treatment allocation is blinded in India but open-label in Australia due to interruptions to placebo supply in the latter. The primary endpoint is a 7-point ordinal scale of clinical states, ranging from no limitation of activities (category 1) to death (category 7), assessed on day 14. Secondary outcomes include the 7-point scale assessed at day 28 and 28- and 90-day mortality. The design adapts the sample size based on accumulating data via frequent interim analyses and the use of predictive probability to determine whether the current sample size is sufficient or continuing accrual would be futile. The trial commenced recruitment on 18 August 2020.
\end{abstract}

Trial registration: ClinicalTrials.gov, NCT04394117. Registered on 19 May 2020. Clinical Trial Registry of India: CTRI/ 2020/07/026831)

Keywords: COVID-19, Angiotensin receptor blockers, Renin-angiotensin system, RCT, Bayesian adaptive design

\footnotetext{
* Correspondence: arlen.wilcox@sydney.edu.au

${ }^{+}$Carinna Hockham and Sradha Kotwal should be considered joint first authors.

†Vivekanand Jha and Meg Jardine should be considered joint senior authors.

${ }^{1}$ The George Institute for Global Health, University of New South Wales,

Sydney, Australia

${ }^{4}$ NHMRC Clinical Trials Centre, University of Sydney, Sydney, Australia

Full list of author information is available at the end of the article
}

(c) The Author(s). 2021 Open Access This article is licensed under a Creative Commons Attribution 4.0 International License, which permits use, sharing, adaptation, distribution and reproduction in any medium or format, as long as you give appropriate credit to the original author(s) and the source, provide a link to the Creative Commons licence, and indicate if changes were made. The images or other third party material in this article are included in the article's Creative Commons licence, unless indicated otherwise in a credit line to the material. If material is not included in the article's Creative Commons licence and your intended use is not permitted by statutory regulation or exceeds the permitted use, you will need to obtain permission directly from the copyright holder. To view a copy of this licence, visit http://creativecommons.org/licenses/by/4.0/ The Creative Commons Public Domain Dedication waiver (http://creativecommons.org/publicdomain/zero/1.0/) applies to the data made available in this article, unless otherwise stated in a credit line to the data. 


\section{Article summary}

Strengths and limitations of this study

- CLARITY will test the effectiveness of repurposing a widely available class of medications for the treatment of COVID-19.

- The risk of COVID-19 transmission is minimised by restricting trial-specific in-person encounters between participants and health care workers.

- The trial burden on sites is reduced by aligning trial processes with routine clinical care and targeting study data collection to measures of COVID-19related effectiveness and selected safety endpoints.

- Adaptive Bayesian sample size re-estimation methodology are employed to protect the trial from an indeterminate result, an approach chosen because of the absence of information on potential effect size.

- The unavoidable use of open-label study medication in Australia is a limitation but is offset by the inclusion of a large number of sites in India (where placebo is available) and mitigated by the blinding of the central study team, including trial statisticians.

\section{Background}

Coronavirus disease 2019 (COVID-19) is a recent and one of the deadliest examples of cross-species viral transmission affecting the human population. By the end of July 2021, COVID-19 has resulted in more than 190 million confirmed cases and 4.1 million confirmed deaths worldwide [1,2]. Its clinical spectrum is broad, ranging from asymptomatic infection to respiratory failure, multi-organ dysfunction, and death [3-7]. Risk factors for very severe disease, which generally manifests as acute respiratory distress syndrome (ARDS), interstitial pneumonia and/or sepsis, consistently include male sex; older age ( $\geq 60$ years) $[8,9]$; pre-existing comorbidities, such as hypertension, diabetes, heart failure, chronic kidney disease, and chronic respiratory illness [10]; and obesity (body mass index $[\mathrm{BMI}] \geq 30 \mathrm{~kg} / \mathrm{m}^{2}$ ) $[11,12]$.

Whilst there have been unprecedented advances in public health and clinical strategies, therapeutics and vaccine development for reducing the impact of COVID-19, outbreaks of the severe acute respiratory syndrome coronavirus 2 (SARS-CoV-2) pandemic continue, with emerging variants adding to uncertainty on its curtailment [13-15]. Widely available, low-cost effective treatments that can be easily and quickly implemented in diverse settings would help ameliorate outbreaks whilst more definitive solutions are found.

SARS-CoV-2 causes COVID-19 through binding to angiotensin-converting enzyme 2 (ACE2) [16, 17], a transmembrane protein and key regulator of the reninangiotensin system (RAS) [18]. Cell entry through binding to ACE2 has been demonstrated for SARS-CoV-2 in in vitro studies $[16,18]$ and for the homologous SARSCoV-1 [19] in a preclinical model [20]. Viral-binding of ACE2 may lead to downregulation of membrane ACE2, causing a dysregulated local RAS that favours inflammation and ongoing tissue damage secondary to excess angiotensin II [21, 22]. Systemic effects are also possible because the dysregulated local RAS is associated with prolonged shedding of the catalytically active site of ACE2 into the circulation [22]. The angiotensin II type 1 receptor (AT1R) may play a key role in COVID-19 pathophysiology as the normal physiological process of ACE2 receptor-mediated endocytosis is dependent on the AT1R and a number of the downstream steps involved in the dysregulation of the local RAS may be mediated by the AT1R [23]. Correlative evidence is provided by the finding that AT1R blockers (angiotensin receptor blockers [ARBs]) reverse the inflammatory impact of coronavirus spike-protein binding to ACE2 in a preclinical model of SARS-CoV-1 disease [20].

ARBs are a commonly prescribed, widely available and affordable class of medications that are used to treat a range of chronic conditions, including hypertension, heart failure, and chronic kidney disease [24]. Observational data suggest that treatment with ARBs could be protective in viral pneumonias, including influenza [25]. The majority of evidence on the role of RAS inhibitors (ARBs and ACE inhibitors) in COVID-19 has been derived from reports of outcomes in prevalent users of RAS inhibitors, both from observational studies and from randomised controlled trials [26-28]. Two reported open-label trials randomised prevalent users of RAS inhibitors contracting COVID-19 to continuation or cessation. The BRACE CORONA trial found that continuation or cessation of treatment with RAS inhibitors did not affect the number of days alive and out of hospital or 30-day mortality in 659 participants hospitalised with COVID-19 [29]. Similarly, the REPLACE COVID trial, which randomised prevalent users of RAS inhibitors with COVID-19 to either continue or discontinue RAS inhibitor use, reported no difference on a global rank score of COVID-19 severity or the need for intensive care admission or mechanical ventilation in 152 participants [30]. These trials suggest that continuing RAS inhibition is safe in participants hospitalised with COVID-19 disease who are already established users of RAS inhibitors. The trials are valuable but do not directly address the question of whether the introduction of RAS inhibition in RAS inhibition-naive patients would improve outcomes in COVID-19. Differences in the two scenarios include the timing of RAS inhibition relative to SARS-CoV-2 exposure, the establishment of RAS inhibition effects during early disease, and the time course of the wash-out of RAS inhibition and the associated physiological effects. 
By directly blocking the AT1R and reducing the tissue-damaging effects of angiotensin II, we hypothesise that ARBs will reduce the severity of COVID-19 respiratory clinical outcomes. The Controlled evaLuation of Angiotensin Receptor blockers for COVID-19 respIraTorY disease (CLARITY) trial will test whether treatment with an ARB in addition to standard of care improves clinical outcomes in high-risk COVID-19 patients, compared to standard care alone using a pragmatic trial design.

\section{Methods/design \\ Design overview}

CLARITY is a pragmatic, adaptive, two-arm, multicentre, comparative effectiveness phase III randomised controlled trial, conducted in India and Australia, designed to evaluate whether ARBs reduce the severity of COVID-19 among high-risk patients. The trial, designed in accordance with SPIRIT guidelines, will recruit patients with COVID-19 deemed to be at high risk of severe illness (Supplementary Material-SPIRIT Checklist) [31]. Overarching principles informing study design include (i) minimising the trial burden on clinical staff and participants, for example, through the alignment of trial processes with routine clinical care and prioritisation of essential routinely collected data that can be extracted from existing medical records, (ii) minimising trialmandated in-person encounters that could increase the risk of exposure and transmission, and (iii) improving research efficiency by incorporating adaptive sample size re-estimation methodology with pre-defined rules and processes, an approach chosen given the absence of informative existing data on the potential effect of the intervention.

\section{Study setting}

The trial is designed to enrol participants at risk of severe disease and is being conducted across 25 hospital sites in India and Australia (Supplementary MaterialList of CLARITY Investigators and study sites), in line with local standard clinical processes. As a result, in India, participants are recruited from sites providing inpatient care only. In Australia, participants are recruited from trial sites providing inpatient care as well as sites providing regular monitoring and management of community-based patients. The majority of study recruitment is now expected to take place in India given the relatively larger number of people affected with COVID-19 in India.

\section{Eligibility criteria}

The eligibility criteria are broadly designed to recruit participants with active COVID-19 who are at risk of severe disease. Risk of severe disease is deemed to be hospital admission for COVID-19 management or the presence of least one risk factor for severe disease in specialised units managing patients in the community (Australia only) (Table 1). Exclusion criteria are designed to avoid enrolling patients who are at risk of not tolerating the medication, of experiencing adverse effects, or who would be ineligible for use of the ARBs for other indications.

Patients with an estimated Glomerular Filtration Rate $($ eGFR $)<30 \mathrm{~mL} / \mathrm{min} / 1.73 \mathrm{~m}^{2}$ or a serum potassium $>5.2$ $\mathrm{mmol} / \mathrm{L}$ within 3 months prior to randomisation, or an absence of the relevant tests, are excluded. It is expected that most patients requiring hospital care or with the defined high-risk conditions will have had serum creatinine and potassium tests conducted upon admission as part of routine care or in the 3 months prior to diagnosis. Patients without such tests are ineligible to participate. In keeping with the principle of designing the trial so that its requirements align with those of routine care, a higher eGFR threshold for community-based patients is used to avoid a requirement for additional clinical monitoring and faceto-face interactions in community-based patients.

\section{Informed consent, recruitment and randomisation}

Prospective patients are approached by the site's principal investigator or study co-ordinator and provided with a written information sheet, physically or electronically, that remains with them for infection control reasons. Informed consent is obtained verbally either via audiorecording or with appropriate documentation by an independent, third-party witness.

Randomisation takes place within 10 days of the confirmed SARS-CoV-2 diagnosis, using a central interactive web response system that contains a computergenerated randomisation schedule. Participants are randomly assigned in a 1:1 ratio to standard of care plus an ARB or standard of care with or without matched placebo (India and Australia, respectively), stratified by country. In Australia, further stratification is performed by baseline hospital admission status (i.e. admitted to hospital or managed virtually in the community). Unless they withdraw their consent, participants who prematurely discontinue study treatment will continue to be followed according to intention-to-treat (ITT) principles.

Participant recruitment is reviewed weekly by the research team. A close ongoing relationship has been maintained with all sites including regular meetings, newsletters, and phone calls. Challenges associated with recruitment are discussed and troubleshooted at each Executive Trial Steering Committee meeting held monthly.

Trial intervention, blinding, and dose management The intervention is a daily dose of an ARB for 28 days. The intention at the time of study design was for 
Table 1 Eligibility criteria, according to hospital admission status at time of enrolment

\begin{tabular}{|c|c|c|}
\hline Criteria & $\begin{array}{l}\text { Inpatients (India } \\
\text { and Australia) }\end{array}$ & $\begin{array}{l}\text { Virtual care patients } \\
\text { (Australia only) }\end{array}$ \\
\hline \multicolumn{3}{|l|}{ Inclusion } \\
\hline $\begin{array}{l}\text { Laboratory-confirmed active SARS-CoV-2 infection within } 10 \text { days prior to randomisation, using } \\
\text { any locally approved testing method }\end{array}$ & $\checkmark$ & $\checkmark$ \\
\hline Aged $\geq 18$ years & $\checkmark$ & $\checkmark$ \\
\hline \multicolumn{3}{|l|}{ Be at high risk of severe disease, defined as: } \\
\hline - Requiring hospital admission for the management of COVID-19 or, & $\checkmark$ & \\
\hline $\begin{array}{l}\text { - Having at least one of the following risk factors for severe disease: } \\
\text { - Aged } \geq 60 \text { years } \\
\text { - BMl } \geq 30 \mathrm{~kg} / \mathrm{m}^{2} \\
\text { - Diagnosis of diabetes defined as HbA1c } \geq 7 \% \text { and/or use of glucose-lowering medication } \\
\text { - History of cardiovascular disease } \\
\text { - History of chronic respiratory disease } \\
\text { - Current treatment with immunosuppression }\end{array}$ & \pm & $\checkmark$ \\
\hline $\begin{array}{l}\mathrm{SBP} \geq 120 \mathrm{mmHg} \text {, or SBP } \geq 115 \mathrm{mmHg} \text { and receiving treatment with a non-RAAS-inhibitor blood } \\
\text { pressure-lowering agent that can be ceased }\end{array}$ & $\checkmark$ & $\checkmark$ \\
\hline Willing and able to perform trial procedures & $\checkmark$ & $\checkmark$ \\
\hline \multicolumn{3}{|l|}{ Exclusion } \\
\hline $\begin{array}{l}\text { Reduced eGFR in preceding } 3 \text { months, defined as }<30 \mathrm{~mL} / \mathrm{min} / 1.73 \mathrm{~m}^{2} \text { or the absence of an } \\
\text { eGFR test }\end{array}$ & $\checkmark$ & \\
\hline $\begin{array}{l}\text { Reduced eGFR in preceding three months, defined as }<45 \mathrm{~mL} / \mathrm{min} / 1.73 \mathrm{~m}^{2} \text { or the absence of an } \\
\text { eGFR test }\end{array}$ & & $\checkmark$ \\
\hline $\begin{array}{l}\text { Elevated serum potassium, defined as }>5.2 \mathrm{mmol} / \mathrm{L} \text {, within the preceding } 3 \text { months or the } \\
\text { absence of a serum potassium test }\end{array}$ & $\checkmark$ & $\checkmark$ \\
\hline $\begin{array}{l}\text { Receiving treatment with an ACE inhibitor, ARB, aldosterone antagonist, aliskiren or angiotensin } \\
\text { receptor neprilysin inhibitor }\end{array}$ & $\checkmark$ & $\checkmark$ \\
\hline Known intolerance to ARBs & $\checkmark$ & $\checkmark$ \\
\hline Known symptomatic postural hypotension & $\checkmark$ & $\checkmark$ \\
\hline Known biliary obstruction or severe hepatic impairment & $\checkmark$ & $\checkmark$ \\
\hline Inability to take medications by mouth during the first $48 \mathrm{~h}$ after randomisation & $\checkmark$ & $\checkmark$ \\
\hline $\begin{array}{l}\text { Women who are currently pregnant or breast feeding (India) } \\
\text { Or } \\
\text { Women }<51 \text { years without a negative pregnancy test during the previous } 3 \text { days and/or who do } \\
\text { not agree to use adequate contraception during the 28-day treatment period (Australia) }\end{array}$ & $\checkmark$ & $\checkmark$ \\
\hline
\end{tabular}

${ }^{\mathrm{a}}$ As defined by the treating clinician

placebo control where possible, although open label was deemed an acceptable alternative and preferable to not conducting the study at all. In India, where placebo could be sourced, the study intervention is telmisartan, supplied as $40 \mathrm{mg}$ tablets or matching placebo. In Australia, placebo was not available at the time of study commencement due to COVID-19-related interruptions to supply chains and the study was initiated open-label with an intention to pursue placebo procurement if it became available. Australian Principal Investigators were given information on the half-life, receptor binding affinities and pressor effect for common ARBs, and were permitted to select an ARB as per the hospital formulary (detailed in the study Guidance document).

The central study team remain blinded to study allocation in both countries throughout the course of the trial. In India, both the participant and the treating site staff are also blinded to treatment allocation. A separate, unblinded statistician will conduct the pre-planned interim analyses required for reporting to the independent Data Safety Monitoring Board (DSMB).

In both countries, treating practitioners are encouraged to commence treatment with a low to moderate starting dose (or placebo) and to increase if tolerated. Study sites are provided guidance on ARB prescribing, monitoring, and adjustment derived from national educational material in the public domain [32, 33]. Individual management decisions on dose initiation, titration, symptom and safety monitoring are at the discretion of the treating team. In the event that prescribing practices are inconsistent with standard guidance, a query will be raised by the study team, but will not constitute a protocol deviation. The study is designed as an effectiveness rather than efficacy trial on the rationale that the 
widespread use of ARBs and the experience of practising clinicians in the study centres with their management means a true effectiveness approach can be tested.

Adherence to ARB prescription and records on daily dosing will be verified using medical records by the study staff. Treating clinicians are encouraged to manage blood pressure according to their usual practices with the caveat that they avoid prescription of ARB and they prioritise cessation or down-titration of concomitant medications rather than study drug for the management of low blood pressure. Daily monitoring of blood pressure of all study participants is recommended. In Australia, community-based participants who are being managed virtually at the time of randomisation are provided an electronic blood pressure monitor and instructed on its use. Clinicians and patients are advised to avoid non-steroidal anti-inflammatory agents (NSAI Ds) during the 28-day treatment period. Regular monitoring of serum potassium is recommended for inpatients, as would be consistent with routine clinical care for hospitalised patients.

\section{Unblinding procedures (India only)}

In the event that knowledge of the treatment will significantly influence a participant's clinical management, emergency unblinding will be permitted via a 24-h emergency unblinding phone line staffed by an authorised representative. The decision to unblind ultimately rests with the Principal Investigator at the site or the treating/ attending clinician.

\section{Primary outcome}

The primary outcome is a 7-point ordinal categorical scale of clinical outcomes, assessed on day 14 (Table 2), modelled via a proportional odds cumulative logistic regression model, and the treatment difference will be assessed via the log-odds. This is a modified version of the 9-point scale recommended by the WHO Research and Development Blueprint expert group and has been used in other COVID-19 trials [34]. The scale captures a broad spectrum of COVID-19 clinical severity and can be derived from the medical record or by phone calls with participants. The scale used in the CLARITY trial was simplified as the original scale includes a category for uninfected with no viral DNA as well as asymptomatic with viral RNA detected. These categories were omitted because viral RNA collection was not mandated in the trial to avoid additional patient encounters beyond routine care.

\section{Secondary and exploratory outcomes}

Secondary and exploratory outcomes are selected because they reflect the clinical severity of COVID-19 disease or are well-known adverse events related to ARBs. They include the 7-point ordinal scale assessed at day 28; 28- and 90-day all-cause mortality (binary outcome); any requirement for intensive care unit (ICU) admission between baseline and days 28 and 90 (binary outcomes); median length of ICU stay, in days, between baseline and day 90; any occurrence of respiratory failure (defined as requirement for non-invasive or invasive mechanical ventilation) (binary outcome); occurrence of kidney failure (defined as the requirement for dialysis) (binary outcome); median number of dialysis days between baseline and day 28; median length of hospital stay, in days, between baseline and days 28 and 90; median number of ventilator-free days between baseline and days 28; presence or absence of acute kidney injury (AKI); and presence or absence of hypotension requiring vasopressors.

Exploratory outcomes include any occurrence of hyperkalaemia between baseline and day 28 (defined as any serum potassium result $>6.0 \mathrm{mmol} / \mathrm{L}$ ) (binary outcome) and the proportional outcome of oxygen $\left(\mathrm{O}_{2}\right)$ saturation/fraction of inspired $\left(\mathrm{FiO}_{2}\right)$ at days 8 and 14 .

\section{Safety monitoring}

Other than the pre-specified outcomes, serious adverse events will not be collected in recognition of the repurposing nature of the trial. The safety profile of ARBs has been well-established in large, randomised trials, and the size of this study will be insufficient to establish whether the safety profile in the COVID-19 setting is significantly different from that already observed in non-COVID-19

Table 2 Seven-point ordinal categorical primary endpoint of the CLARITY trial

\begin{tabular}{ll}
\hline Category & Description \\
\hline 1 & Not hospitalised with no limitation on activities \\
2 & Not hospitalised with some limitation on activities \\
3 & Hospitalised, not requiring supplemental oxygen \\
4 & Hospitalised, requiring supplemental oxygen \\
5 & Hospitalised, requiring non-invasive mechanical ventilation or high-flow nasal cannular (HFNC) therapy \\
6 & Hospitalised, requiring mechanical ventilation \pm additional organ support \\
7 & Died \\
\hline
\end{tabular}


settings. The safety events of hypotension, hyperkalaemia, or increases in serum creatinine will be collected as secondary outcomes. These events were selected as welldescribed events associated with ARB use.

\section{Follow-up schedule}

Participants are followed up daily between day 0 and day 28, and once at day 90 (Figs. 1 and 2).

The trial does not mandate pre-specified face-to-face visits or additional biochemical testing specific to ARBs beyond that required as part of routine clinical care. This is in accordance with the effectiveness nature of the trial and the rationale that the well-known safety profile and familiarity of these medications does not warrant the infection risk related to visits that are not essential for clinical care. For the most part, participants will not be followed up outside of routine care, unless additional information on blood pressure, medication adherence, and clinical health status is required. This will be performed remotely, via telephone contact only.

\section{Data collection}

De-identified trial data will be collected directly from patients' medical records and entered electronically into trial-specific electronic case report forms (eCRFs). Where appropriate, these data will be supplemented with information provided by the treating staff or participants themselves (e.g. information relating to medication adherence and blood pressure). The eCRFs are housed within a REDCap (Research Electronic Data Capture) database [35, 36], a secure, web-based application, hosted on secure servers in India and Australia, respectively, and backed up daily. All trial data will be stored in keeping with local regulatory requirements and accessed only by approved study personnel.

Data that are essential for assessing the primary outcome and relevant secondary outcomes will be collected daily for the first 28 days. This includes information on blood pressure, dialysis requirement, any serum creatinine and serum potassium levels, medication adherence, and clinical health status on the 7-point ordinal scale. The timing of serum creatinine and serum potassium testing will be determined by treating staff and will be monitored by study staff. As above, safety monitoring practices that are inconsistent with standard guidance will be queried by the study team but will not constitute a protocol deviation. All other secondary and exploratory outcomes will be extracted from the patients' medical records after days 28 and 90. In the event that a patient is discharged from hospital or stops receiving virtual care prior to day 14, follow-up of the primary outcome will be performed via telephone contact. Other secondary outcomes will be collected from patient's medical records or via telephone contact after day 90 . No biological specimens will be collected as part of the trial; however, the study consent includes an optional consent to retain, store, and use leftover blood samples obtained during routine clinical care for further research, for another, separate, ethically approved research project based at one Australian site (Austin Health). Adjudication of study endpoints will not be performed.

\section{Statistical considerations}

In the absence of prior information on the potential effect size of ARBs on COVID-19 severity, the trial will follow adaptive sample size re-estimation principles. This approach protects the trial against an indeterminate

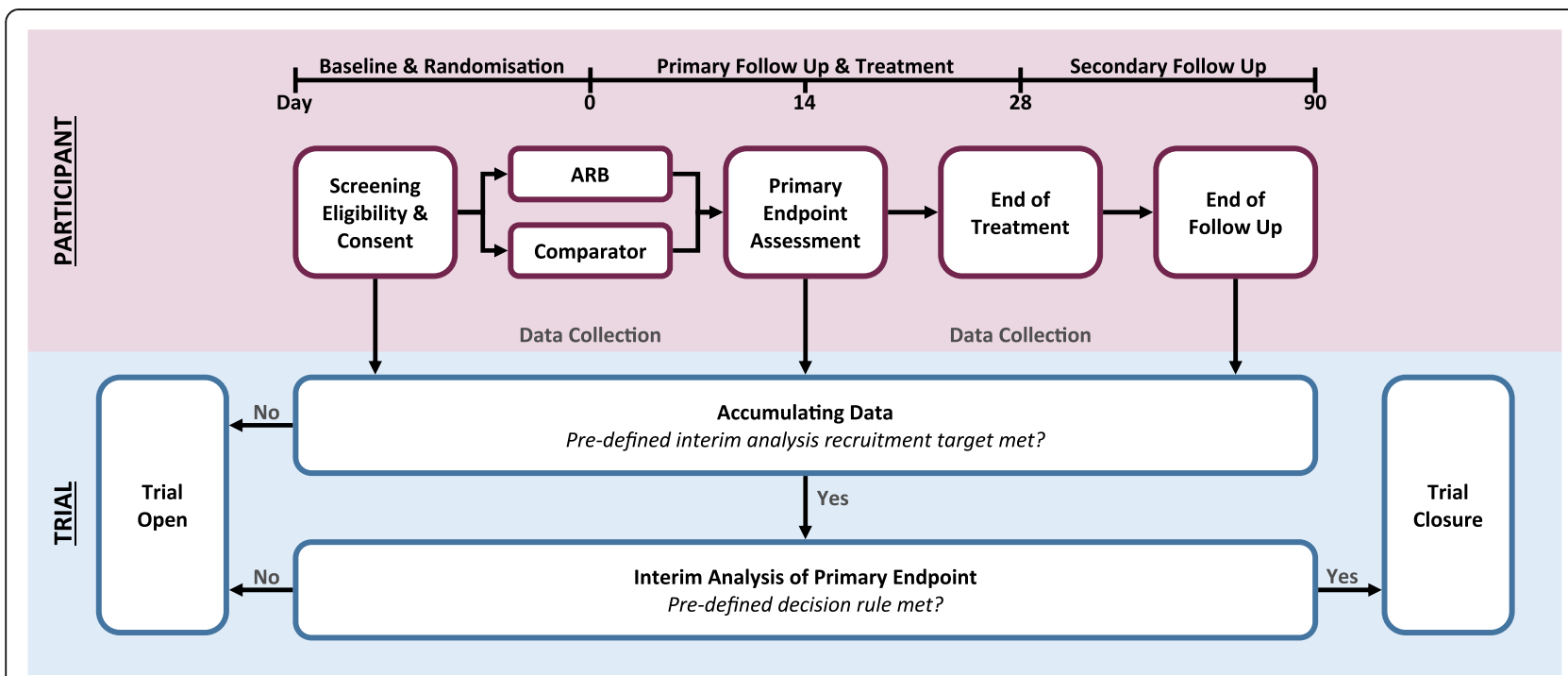

Fig. 1 Trial overview and participant schedule 


\begin{tabular}{|c|c|c|c|c|c|c|c|c|c|c|c|c|c|c|c|c|c|c|}
\hline \multirow{2}{*}{$\frac{\text { Time Point }}{\text { Day }}$} & \multirow{2}{*}{$\frac{S}{<B}$} & \multirow{2}{*}{$\frac{B}{0}$} & \multicolumn{15}{|c|}{$1^{\circ}$ Follow Up \& Treatment Period } & \multirow{2}{*}{$\begin{array}{c}2^{\circ} \text { Follow } \\
\text { Up } \\
29-90\end{array}$} \\
\hline & & & 1 & 2 & 3 & 4 & 5 & 6 & 7 & 8 & 9 & 10 & 11 & 12 & 13 & 14 & $15-28$ & \\
\hline Eligibility & $\mathrm{X}$ & & & & & & & & & & & & & & & & & \\
\hline Consent & $\mathrm{X}$ & & & & & & & & & & & & & & & & & \\
\hline Demographics $^{1}$ & & $\mathrm{X}$ & & & & & & & & & & & & & & & & \\
\hline Medical History & & $\bar{X}$ & & & & & & & & & & & & & & & & \\
\hline Randomisation & & $\mathrm{X}$ & & & & & & & & & & & & & & & & \\
\hline Concomitant Medication & & $\bar{X}$ & $\mathrm{X}$ & $\mathrm{X}$ & $\mathrm{X}$ & $\mathrm{X}$ & $\mathrm{X}$ & $\mathrm{X}$ & $\mathrm{X}$ & $\mathrm{X}$ & $\mathrm{X}$ & $\mathrm{X}$ & $\mathrm{X}$ & $\mathrm{X}$ & $x$ & $\mathrm{X}$ & $\mathrm{X}$ & \\
\hline Intervention Supply & & $\mathrm{X}$ & & & & & & & & & & & & & & & & \\
\hline Health Status Assessment ${ }^{2}$ & & $\bar{X}$ & $\mathrm{X}$ & $\mathrm{X}$ & $\mathrm{X}$ & $\mathrm{X}$ & $\mathrm{X}$ & $\bar{X}$ & $\bar{X}$ & $\mathrm{X}$ & $\mathrm{X}$ & $\mathrm{X}$ & $\mathrm{X}$ & $\mathrm{X}$ & $\mathrm{X}$ & $\mathrm{X}$ & $\mathrm{X}$ & $\mathrm{X}$ \\
\hline Medication Adherence & & $\mathrm{X}$ & $\mathrm{X}$ & $\mathrm{X}$ & $\mathrm{X}$ & $\mathrm{X}$ & $\mathrm{X}$ & $\bar{x}$ & $\mathrm{X}$ & $\mathrm{X}$ & $\mathrm{X}$ & $\mathrm{X}$ & $\mathrm{X}$ & $\mathrm{X}$ & $\mathrm{X}$ & $\mathrm{X}$ & $\mathrm{X}$ & \\
\hline Blood Pressure & & $\bar{X}$ & $\mathrm{X}$ & $\bar{X}$ & $\mathrm{X}$ & $\mathrm{X}$ & $\mathrm{X}$ & $\mathrm{X}$ & $\bar{X}$ & $\mathrm{X}$ & $\mathrm{X}$ & $\mathrm{X}$ & $\mathrm{X}$ & $\mathrm{X}$ & $\mathrm{X}$ & $\bar{X}$ & & \\
\hline Blood Pathology ${ }^{3}$ & & $\mathrm{x}$ & $\mathrm{X}$ & & $\mathrm{x}$ & & $\mathrm{X}$ & & $\mathrm{X}$ & & $\mathrm{x}$ & & & & & $x$ & & \\
\hline Hospitalisation \& Mortality & & & & & & & & & & & & & & & & & & $\mathrm{X}$ \\
\hline \multicolumn{19}{|c|}{$\begin{array}{l}S=\text { Screening, } B=\text { Baseline, } 1^{\circ}=\text { Primary, } 2^{\circ}=\text { Secondary } \\
1 \text { Demographics includes: Date of Birth, Sex, Ethnicity, Weight, Height, Smoking Status, COVID-19 diagnosis, comorbidities } \\
2 \text { Health Status Assessment includes: Hospital Admission status, Ventilation status, Supplemental Oxygen Status, Intensive Care Unit } \\
\text { Admission status, Mortality status, Dialysis Status \& Acute Kidney Injury status } \\
3 \text { Blood Pathology includes: Potassium, Serum Creatinine, creatinine kinase, estimated glomerular filtration rate, white cell count, } \\
\text { lymphocytes, D-dimer, C-reactive protein }\end{array}$} \\
\hline
\end{tabular}

result, whilst avoiding over-sampling. The study uses Bayesian methods to model the outcomes of interest at pre-planned interim analyses. All inferences will be based on the joint posterior distribution of the model parameters, and this distribution will be sampled using Markov chain Monte Carlo methods.

\section{Primary and secondary analyses}

The estimated treatment effect on the primary endpoint will be expressed as the common odds ratio, corresponding to the odds of a better outcome in the ARB versus the comparator arm on the 7-point ordinal scale at day 14 and its $95 \%$ credible interval. This will be modelled using a proportional odds logistic regression model [37], further details of which are provided in the statistical analysis plan, which will be published separately. The assessment of the primary endpoint at day 14 reflects the timeframe within which most SARS-CoV-2positive patients have either developed severe disease or begun to recover [3].

The primary analysis will be an ITT analysis, whereby comparisons will be made between all participants randomised to the treatment arms irrespective of whether they received or completed their course of allocated treatment.

Secondary analyses will comprise assessment of the primary endpoint in patients who were randomised and treated as per the trial protocol (i.e. per-protocol population), as well as analyses of pre-specified secondary and exploratory outcomes, using statistical models that are appropriate for the specific outcome.

Analyses of the primary endpoint will be Bayesian. Details of these approaches, and how missing data will be handled, are described in the statistical analysis plans

\section{Sample size, interim analyses, and stopping rules}

Prior to the start of the trial, trial simulations were performed to evaluate the trial operating characteristics under a range of scenarios, data configurations, interim timings, and decision thresholds (1000 simulations for every scenario). A maximum sample size of 2200 was applied. The simulations showed that, across a variety of scenarios, the trial is expected to yield a power $>80 \%$ if the odds ratio for the intervention is $\geq 1.25$, with the chance of declaring a false positive being $<0.08$. Of note, the average sample size required to achieve this was considerably lower than the imposed maximum sample size of 2200. Further details of these simulations, the different scenarios considered, and their underlying assumptions will be provided in the statistical analysis plan prior to the first scheduled interim analysis.

The first interim analysis will be conducted 14 days after the 700th participant has been enrolled. Thereafter, an interim analysis will be conducted approximately 14 days after every 300 additional participants have been enrolled (to ensure follow-up is reached for the last enrolled patient) until the trial stops or the maximum sample size of 2200 has been reached. All interim analyses will be based on the primary outcome. At each interim analysis, the predictive probability that the intervention is effective, or that the trial is futile, will be estimated and assessed against pre-defined decision thresholds

Table 3 Pre-specified decision rules for the CLARITY trial. Details about how these probabilities are evaluated/approximated are available in the statistical analysis plan

\begin{tabular}{lll}
\hline Reason for stopping & Posterior probability & Decision rule \\
\hline Effectiveness & $\operatorname{Pr}(\mathrm{OR}<\log (1.00))>0.975$ & $>0.95$ \\
Futility & $\operatorname{Pr}(\mathrm{OR}<\log (1.00))>0.975$ & $<0.02$ \\
\hline
\end{tabular}


(Table 3). In both cases, the predictive probability of success will be computed by averaging over the predictive distribution of the response. For effectiveness, this will be calculated for participants who have been randomised but not yet responded, or who have completed their 14-day treatment period. If the predictive probability is greater than the decision threshold of 95\% (Table 3 ), then a recommendation is put forward to the DSMB that the trial be stopped for effectiveness. For futility, the calculation is performed for the participants who have been randomised but not yet responded as well as those who have not been enrolled, up to the maximum sample size of 2200 . If the predictive probability indicates that fewer than $2 \%$ of the trials detect a treatment benefit, a recommendation is put forward to the DSMB that the trial be stopped for futility.

\section{Study oversight}

Oversight of the CLARITY trial is provided by the Trial Steering Committee. A Consumer and Community Engagement Committee assists the Trial Steering Committee, providing advice and feedback on trial design and participant-facing documents. An independent DSMB is responsible for reviewing interim analysis results in a unblinded manner and advising on overall participant safety.

The Trial Steering Committee Executive Committee provides additional supervision of the operational aspects of the trial. Within the pandemic setting, limitations are placed on hospital and health research systems limiting in-person interactions. On-site monitoring will not be performed for CLARITY, remote monitoring and auditing will be performed.

\section{Interactions with other trials}

In the current pandemic setting, clinical sites may have multiple research projects being conducted that require patient participation. CLARITY encourages coenrolment in other trials (provided that the intervention does not relate to RAS inhibition) in order to maximise the generation of evidence. Sites are encouraged to coordinate recruitment approaches for trials involving participants with COVID-19.

\section{Ethical considerations and dissemination}

The CLARITY trial will be conducted in accordance with the principles of the Declaration of Helsinki, the National Ethical Guidelines for Biomedical and HealthRelated Research Involving Human Participants in India and the National Statement on Ethical Conduct in $\mathrm{Hu}$ man Research in Australia. The study has received ethical approval from The George Institute for Global Health Ethics Committee in India (ref. no. 14/2020) and the Sydney Local Health District Ethics Review
Committee (Royal Prince Alfred Hospital Zone) (Code: EC0113) in Australia (ref. no. X20-0118 \& 2020/ ETH00742). The trial design was informed by specific guidance including ethical principles relevant to the conduct of COVID-19 trials [38, 39]. Any substantial changes to the protocol will be submitted to the primary approving ethics committee in each country for approval and then communicated with sites and investigators in line with local regulatory processes.

A pre-formatted template has received pre-approval by the relevant Ethics committees to allow rapid dissemination of results to surviving participants at the conclusion of the trial (Supplementary Material-CLARITY Trial Results Template). The results of the trial will be submitted for publication in international peer-reviewed journals and for presentation at national and international conferences.

\section{Trial status}

The protocol version is number 3.0, dated 29 October 2020. The trial commenced recruitment on 18 August 2020 and is ongoing.

\section{Discussion}

The COVID-19 pandemic is now in its second year. The discovery of effective vaccines has been a very anticipated and welcome development. Some therapies have been found to improve outcomes including corticosteroids $[40,41]$, the IL- 6 receptor antagonists, tocilizumab and sarilumab $[42,43]$, and the anti-viral agent, remdesivir [44]. However, these are not universally available and importantly have not eliminated the disease. With only a minority of the world's population vaccinated, the emergence of multiple viral variants and the predictions of secondary and tertiary waves of infection unfortunately realised, more treatments are needed for COVID-19 disease. Investigating existing medications with a known safety profile and widespread availability in a scientifically robust manner offers an efficient approach to finding treatments that can be rapidly and widely implemented. The CLARITY trial is a pragmatic, minimally intrusive trial that aims to achieve this.

Observational data have shown that prevalent use of ARBs at the time of contracting COVID-19 is associated with either better or similar outcomes compared with people who are not receiving ARB treatment [26]. Moreover, there is randomised evidence that continuation versus withdrawal of RAS inhibitors in COVID-19 patients with an existing indication for these medications does not impact the clinical outcome of COVID-19 [29, 30]. Whilst the withdrawal of these agents does not appear to worsen the course of COVID-19 disease, the addition of RAS blockade may yet improve outcomes due to factors such as presence of blockade at the time 
of infection, pharmacokinetic wash-out time, and physiological time to response. There is currently no randomised evidence for the effect of the initiation of ARBs on the course of disease in participants with newly diagnosed COVID-19 disease [27]. CLARITY is one of 12 trials registered on ClinicalTrials.gov (as of March 18 2021) that will test this hypothesis. Individually or in aggregate, these trials promise to shed light on the ability of RAS blockade to improve outcomes in COVID-19 disease.

The experience of research in the pandemic has generated some lessons for the conduct of research in general. The pandemic has highlighted the extent to which welldesigned and supported research and health systems can respond to an unanticipated need for evidence generation. The UK has stood out for its success in generating evidence for the clinical management of COVID-19 disease. The established research and health infrastructure of the National Institute for Health Research (NIHR) embedded within the National Health Service (NHS) [45] has meant trials could be, and were, rapidly deployed using pre-existing systems. As a result, the NIHR has supported a total of 91 COVID-19 studies [46], including the well-known RECOVERY trial, which has been at the forefront of COVID-19 evidence generation. The clear illustration of the clinical benefits that can be derived from research systems embedded in clinical practice will hopefully inspire health system custodians long after the pandemic has passed.

The pandemic setting has also inspired review by oversight bodies on the necessity and justification of common trial features [47-49]. The result has been an increase in the uptake of recent initiatives such as virtual study visits and streamlined trial procedures [50, 51]. Review of the success of these measures will hopefully inspire the greater adoption of technology to reduce the burden of research participation on patients and lead to greater research efficiency.

Lastly, there has been the development of specific guidance on the ethical principles informing the design and conduct of COVID-19 research, such as requirements to consider the impact of COVID-19 research on participant safety, on potentially strained health systems and on the safety of research staff [39]. These considerations have informed the development and conduct of the CLARITY trial, including the comparative effectiveness nature of the trial, the low demands made on clinical staff and the minimisation of trial-specific in-person encounters. The broad adoption of a more deliberate approach to appropriate trial features for specific settings may foster better integration of research and clinical practice, resulting in increased evidence generation, trial efficiencies and the clinical benefits resulting from research.

\section{Conclusion}

Despite remarkable advances in the evidence-based treatment of COVID-19, it remains unclear whether treatment with $\mathrm{ARBs}-\mathrm{a}$ readily available and low-cost class of medications-can reduce COVID-19 severity in patients who are otherwise not indicated. CLARITY is a pragmatic, multi-centre randomised controlled trial designed to assess the effectiveness of ARBs in reducing disease severity in COVID-19. As one of only two largescale ARB trials currently recruiting in the Asia-Pacific region, CLARITY will make important contributions to the global evidence base for whether this class of medications are effective in the treatment of COVID-19. If found to be effective, the implementation of ARB treatment for COVID-19 into clinical practice is likely to be rapid.

\section{Supplementary Information}

The online version contains supplementary material available at https://doi. org/10.1186/s13063-021-05521-0.
Additional file 1. CLARITY Trial Team.
Additional file 2. CLARITY Participant Information and Informed Consent Document (in English).

Additional file 3. CLARITY SPIRIT Fillable Checklist.

Additional file 4. CLARITY Trial Results Template.

Additional file 5. CLARITY WHO Trial Registration Data.

\section{Acknowledgements}

We thank all the participants in the CLARITY trial and the doctors, nurses, pharmacists, and research staff at participating sites who ensure the successful implementation of the trial. We thank the CLARITY Consumer Engagement Committee for their helpful input into trial design and participant-facing materials and the operational staff at The George Institute for Global Health in Australia and India. MJa is supported by a Medical Research Future Fund Next Generation Clinical Researchers Program Career Development Fellowship.

\section{Authors' contributions}

$C H, S K, A W, A B, J M, C P, L B, N B, M K, E L, C J, A M, T S, M J o n, V J$, and MJa made substantial contributions to the conception and design of the CLARITY study. $\mathrm{CH}, \mathrm{SK}, \mathrm{AW}, \mathrm{EL}$, and MJa drafted the protocol. All authors read, edited, and approved the manuscript for submission. Authorship guidelines will follow the ICMJE recommendations. We do not plan to use professional writers.

\section{Funding}

CLARITY is supported by the Australian Government's Medical Research Future Fund Respiratory Medicine Clinical Trials Research on COVID-19 2020 grant scheme (ref. no. APP2002277).

\section{Availability of data and materials}

A pre-formatted template has received pre-approval by the relevant Ethics committees to allow rapid dissemination of results to surviving participants at the conclusion of the trial (Supplementary Material_CLARITY Trial Results Template). The results of the trial will be submitted for publication in international peer-reviewed journals and for presentation at national and international conferences. Surviving participants will be individually notified of trial findings.

The final data set will be under the custodianship of the Chair of the Trial Steering Committee. All individual participant data that are collected during the trial will be de-identified. The researchers intend deidentified data will contribute to global learnings through an appropriately constituted individual participant data level collaboration. Requests for data access or analysis 
proposals will be reviewed by the Trial Steering Committee, who will assess proposals according to criteria based on scientific merit and contribution to global knowledge. Data sharing will be performed in compliance with local Data Protection Laws. The study protocol, statistical analysis plan, and informed consent form will be publicly available prior to the completion of the trial.

\section{Declarations}

\section{Ethics approval and consent to participate}

Ethical approval was received from the Sydney Local Health District Ethics Review Committee (Royal Prince Alfred Hospital Zone; Code: EC0113) in Australia (X20-0118 \& 2020/ETH00742) and The George Institute for Global Health Ethics Committee in India (14/2020). Prospective patients are provided with an ethically approved written information sheet, physically or electronically, that remains with them for infection control reasons. Informed consent is obtained verbally either via audio-recording or with appropriate documentation by an independent, third-party witness.

\section{Consent for publication}

Not applicable.

\section{Competing interests}

$\mathrm{CH}, \mathrm{SK}, \mathrm{AW}, \mathrm{AB}, \mathrm{JM}, \mathrm{LB}, \mathrm{NB}, \mathrm{MK}, \mathrm{VR}, \mathrm{MJ}$ h, EL, AR, AM, TS, and MJon have no conflicts of interest to disclose.

CP serves on advisory boards for AstraZeneca, Boehringer Ingelheim, Merck Sharp and Dohme, and Novartis.

CJ serves on advisory boards for AstraZeneca, Boehringer Ingelheim, Chiesi, GlaxoSmithKline, Novartis, and Sanofi-Genzyme.

VJ has received grants from Baxter Healthcare, Biocon, and GlaxoSmithKline and speaker fees/advisory board from AstraZeneca, Baxter Healthcare, NephroPlus, and Sanofi-all outside the submitted work. All fees paid to the organisation.

MJar is responsible for research projects that have received unrestricted funding from Amgen, Baxter, Bayer, CSL Behring, Eli Lilly, Gambro, and Merck Sharp and Dohme; has served on advisory boards sponsored by Akebia, AstraZeneca, Baxter, Bayer, Boehringer Ingelheim, Merck Sharp and Dohme, and Vifor; serves on the Steering Committee for trials sponsored by Chinook, CSL Behring, and Janssen; serves on a Steering Committee for an investigator-initiated trial in COVID-19 disease with funding support from Dimerix; spoken at scientific meetings sponsored by Amgen, Janssen, Roche, and Vifor; with any consultancy, honoraria, or travel support paid to the institution.

\section{Author details}

${ }^{1}$ The George Institute for Global Health, University of New South Wales, Sydney, Australia. ${ }^{2}$ The George Institute for Global Health, Imperial College London, London, UK. ${ }^{3}$ Prince of Wales Hospital, Sydney, Australia. ${ }^{4}$ NHMRC Clinical Trials Centre, University of Sydney, Sydney, Australia. ${ }^{5}$ The George Institute for Global Health, New Delhi, India. ${ }^{6}$ Queensland University of Technology, Brisbane, Australia. ${ }^{7}$ Royal North Shore Hospital, Sydney, Australia. ${ }^{8}$ Kolling Institute of Medical Research, University of Sydney, Sydney, Australia. ${ }^{9}$ Department of Medicine, The University of Melbourne, Austin Health, Heidelburg, Victoria, Australia. ${ }^{10}$ All India Institute of Medical Sciences, Raipur, India. ${ }^{11}$ Christian Medical College, Ludhiana, India. ${ }^{12}$ Concord Repatriation General Hospital, Sydney, Australia. ${ }^{13}$ The University of Sydney, Sydney, Australia. ${ }^{14}$ Sydney School of Public Health, University of Sydney, Sydney, Australia. ${ }^{15}$ The Sydney Children's Hospitals Network, Westmead, NSW, Australia.

Received: 7 June 2021 Accepted: 6 August 2021

Published online: 28 August 2021

\section{References}

1. Ritchie H, Ortiz-Ospina E, Beltekian D, et al. Coronavirus (COVID-19) cases 2021 [Available from: https://ourworldindata.org/covid-cases]. Accessed May 12021.

2. Johns Hopkins University and Medicine COVID-19 Dashboard. Johns Hopkins Coronavirus Resource Centre [Available from: https://coronavirus. jhu.edu/map.html]. Accessed May 152020.
3. Docherty AB, Harrison EM, Green CA, Hardwick HE, Pius R, Norman L, et al. Features of 20133 UK patients in hospital with covid-19 using the ISARIC WHO Clinical Characterisation Protocol: prospective observational cohort study. BMJ. 2020;369:m1985. https://doi.org/10.1136/bmj.m1985.

4. International Severe Acute Respiratory and Emerging Infections Consortium (ISARIC). COVID-19 Report: 19 May 2020,2020.

5. Lechien JR, Chiesa-Estomba CM, Place S, et al. Clinical and epidemiological characteristics of 1420 European patients with mild-to-moderate coronavirus disease 2019. J Intern Med. 2020;288(3):335-44. https://doi.org/1 $0.1111 /$ joim.13089.

6. Parasher A. COVID-19: Current understanding of its pathophysiology, clinical presentation and treatment. Postgrad Med J.2020:postgradmedj-2020138577. https://doi.org/10.1136/postgradmedj-2020-138577.

7. W-j G, Z-y N, Hu Y, et al. Clinical characteristics of coronavirus disease 2019 in China. N Engl J Med. 2020.https://doi.org/10.1056/NEJMoa2002032.

8. Wu Z, McGoogan JM. Characteristics of and important lessons from the coronavirus disease 2019 (COVID-19) outbreak in China: summary of a report of 72314 cases from the Chinese Center for Disease Control and Prevention. JAMA. 2020;323(13):1239-42. https://doi.org/10.1001/jama.2020.2 648.

9. Center for Disease Control and Prevention. Coronavirus disease 2019 (COVID-19): older adults Sep 2020 [Available from:https://www.cdc.gov/ coronavirus/2019-ncov/need-extra-precautions/older-adults.html]. Accessed 22 Feb 2021.

10. Williamson EJ, Walker AJ, Bhaskaran K, Bacon S, Bates C, Morton CE, et al. Factors associated with COVID-19-related death using OpenSAFELY. Nature. 2020;584(7821):430-6. https://doi.org/10.1038/s41586-020-2521-4.

11. Peters SAE, MacMahon S, Woodward M. Obesity as a risk factor for COVID19 mortality in women and men in the UK biobank: comparisons with influenza/pneumonia and coronary heart disease. Diabetes Obes Metab. 2020. https://doi.org/10.1111/dom.14199 [published Online First: 2020/09/ 25].

12. Popkin BM, Du S, Green WD, et al. Individuals with obesity and COVID-19: a global perspective on the epidemiology and biological relationships. Obesity Rev. 2020;21(11):e13128 gercdd.

13. Phillips $\mathrm{N}$. The coronavirus is here to stay - here's what that means. Nature. 2021;590(7846):382-4. https://doi.org/10.1038/d41586-021-00396-2 [published Online First: 2021/02/18].

14. Torjesen I. COVID-19 will become endemic but with decreased potency over time, scientists believe. BMJ. 2021;372:n494. https://doi.org/10.1136/ bmj.n494.

15. Hogan A, Winskill $P$, Watson $O$, et al. Modelling the allocation and impact of a COVID-19 vaccine: Imperial College London; 2020.

16. Hoffmann M, Kleine-Weber H, Schroeder S, Krüger N, Herrler T, Erichsen S, et al. SARS-CoV-2 cell entry depends on ACE2 and TMPRSS2 and is blocked by a clinically proven protease inhibitor. Cell. 2020;181(2):271-280.e8. https://doi.org/10.1016/j.cell.2020.02.052.

17. Lan J, Ge J, Yu J, Shan S, Zhou H, Fan S, et al. Structure of the SARS-CoV-2 spike receptor-binding domain bound to the ACE2 receptor. Nature. 2020 581(7807):215-20. https://doi.org/10.1038/s41586-020-2180-5.

18. Yeung ML, Teng JLL, Jia L, Zhang C, Huang C, Cai JP, et al. Soluble ACE2mediated cell entry of SARS-COV-2 via interaction with proteins related to the renin-angiotensin system. Cell. 2021;184(8):2212-2228.e12. https://doi. org/10.1016/j.cell.2021.02.053.

19. Lu R, Zhao X, Li J, Niu P, Yang B, Wu H, et al. Genomic characterisation and epidemiology of 2019 novel coronavirus: implications for virus origins and receptor binding. Lancet. 2020;395(10224):565-74. https://doi.org/10.1016/ S0140-6736(20)30251-8.

20. Kuba K, Imai $Y$, Rao $S$, et al. A crucial role of angiotensin converting enzyme 2 (ACE2) in SARS coronavirus-induced lunginjury. Nat Med. 2005;11(8):875-9. https://doi.org/10.1038/nm1267. [published Online First: 2005/07/12].

21. Ramchand J, Burrell LM. Circulating ACE2: a novel biomarker of cardiovascular risk. Lancet. 2020;396(10256):937-9. https://doi.org/10.1016/ S0140-6736(20)32011-0.

22. Patel SK, Juno JA, Lee WS, Wragg KM, Hogarth PM, Kent SJ, et al. Plasma ACE2 activity is persistently elevated following SARS-CoV-2 infection: implications for COVID-19 pathogenesis and consequences. Eur Respir J. 2021;2003730(5):2003730. https://doi.org/10.1183/13993003.03730-2020.

23. Deshotels MR, Xia H, Sriramula S, et al. Angiotensin II mediates angiotensin converting enzyme type 2 internalization and degradation through an angiotensin I| type I receptor-dependent mechanism. Hypertension. 2014; 
64(6):1368-75. https://doi.org/10.1161/hypertensionaha.114.03743 [published Online First: 2014/09/17]

24. Terra SG. Angiotensin receptor blockers. Circulation. 2003;107(24):e215-e16. https://doi.org/10.1161/01.CIR.0000072344.12827.13.

25. Chung S-C, Providencia R, Sofat R. Association between angiotensin blockade and incidence of influenza in the United Kingdom. N Engl J Med. 2020;383(4):397-400. https://doi.org/10.1056/NEJMc2005396.

26. Mackey K, King VJ, Gurley S, Kiefer M, Liederbauer E, Vela K, et al. Risks and impact of angiotensin-converting enzyme inhibitors or angiotensin-receptor blockers on SARS-CoV-2 infection in adults. Ann Intern Med. 2020;173(3): 195-203. https://doi.org/10.7326/M20-1515.

27. Mackey K, Kansagara D, Vela K. Update Alert 7: risks and impact of angiotensin-converting enzyme inhibitors or angiotensin-receptor blockers on SARS-CoV-2 infection in adults. Ann Intern Med. 2021;174(2):W25-9. https://doi.org/10.7326/L20-1446.

28. Reynolds HR, Adhikari S, Pulgarin C, Troxel AB, Iturrate E, Johnson SB, et al. Renin-angiotensin-aldosterone system inhibitors and risk of COVID-19. N Engl J Med. 2020;382(25):2441-8. https://doi.org/10.1056/NEJMoa2008975.

29. Lopes RD, Macedo AVS, de Barros E Silva PGM, et al. Effect of discontinuing vs continuing angiotensin-converting enzyme inhibitors and angiotensin II receptor blockers on days alive and out of the hospital in patients admitted with COVID-19: a randomized clinical trial. JAMA. 2021;325(3):254-64. https://doi.org/10.1001/jama.2020.25864.

30. Cohen JB, Hanff TC, William P, Sweitzer N, Rosado-Santander NR, Medina C, et al. Continuation versus discontinuation of renin-angiotensin system inhibitors in patients admitted to hospital with COVID-19: a prospective, randomised, open-label trial. Lancet Respir Med. 2021;9(3):275-84. https:// doi.org/10.1016/\$2213-2600(20)30558-0.

31. Chan A-W, Tetzlaff JM, Altman DG, Laupacis A, Gøtzsche PC, Krleža-Jerić K, et al. SPIRIT 2013 statement: defining standard protocol items for clinical trials. Ann Intern Med. 2013;158(3):200-7. https://doi.org/10.7326/0003-481 9-158-3-201302050-00583.

32. Mount D. Treatment and prevention of hyperkalemia in adults. 2020. uptodatecom

33. Australian Medicines Handbook 2020 (online). Australian Medicines Handbook Pty Ltd Adelaide [updated April 15 2020].Available from: https:/a mhonline.amh.net.au/.

34. Marshall JC, Murthy S, Diaz J, Adhikari NK, Angus DC, Arabi YM, et al. A minimal common outcome measure set for COVID-19 clinical research. Lancet Infect Dis. 2020;20(8):e192-e97. https://doi.org/10.1016/S1473-3099(2 0)30483-7.

35. Harris PA, Taylor R, Minor BL, et al. The REDCap consortium: building an international community of software platform partners. J Biomed Inform. 2019;95:103208. https://doi.org/10.1016/j.jbi.2019.103208.

36. Harris PA, Taylor R, Thielke R, et al. Research electronic data capture (REDCap)--a metadata-driven methodology and workflow process for providing translational research informatics support. J Biomed Inform. 2009; 42(2):377-81. https://doi.org/10.1016/j.jbi.2008.08.010 [published Online First: 2008/10/22].

37. McCullagh P. Regression models for ordinal data. J R Stat Soc Ser B Methodol. 1980;42(2):109-27. https://doi.org/10.1111/j.2517-6161.1980.tb011 09.X.

38. NSW Health. COVID-19 clinical trial guidance for sponsors, sites, researchers, HRECs and RGOs. [Available from: https://www.medicalresearch.nsw.gov.au/ covid-19-clinical-trial-guidance/]. Accessed 25 Mar 2020 1.0.

39. Sydney Local Health District. SLHD Guidance to Investigators on the conduct of clinical trials and clinical studies during theCOVID-19 pandemic. [Available from: https://www.slhd.nsw.gov.au/Concord/ethics\%5Ccontent/ pdf/SLHD_Guidance_CT_and_Clinical_Studies_COVID-19_v2.9.0.pdf]. Accessed 26 Mar 2020 2.9.0.

40. The RECOVERY Collaborative Group. Dexamethasone in hospitalized patients with COVID-19 — Preliminary Report. N Engl J Med. 2020;384(8): 693-704. https://doi.org/10.1056/NEJMoa2021436.

41. The Writing Committee for the REMAP-CAP Investigators. Effect of hydrocortisone on mortality and organ support in patients with severe COVID-19: the REMAP-CAP COVID-19 corticosteroid domain randomized clinical trial. JAMA. 2020;324(13):1317-29. https://doi.org/10.1001/jama.202 0.17022 .

42. The RECOVERY Collaborative Group. Tocilizumab in patients admitted to hospital with COVID-19 (RECOVERY): a randomised, controlled, open-label, platform trial. Lancet. 2021;397(10285):1637-45. https://doi.org/10.1016/S014 0-6736(21)00676-0.

43. Wise J. Covid-19: Arthritis drugs improve survival in intensive care patients, shows study. BMJ. 2021;372:n61. https://doi.org/10.1136/bmj.n61.

44. Beigel JH, Tomashek KM, Dodd LE, Mehta AK, Zingman BS, Kalil AC, et al. Remdesivir for the treatment of COVID-19 - final report. N Engl J Med. 2020;383(19):1813-26. https://doi.org/10.1056/NEJMoa2007764.

45. National Institute for Health Research. Embedding a research culture 2020 [Available from: https://www.nihr.ac.uk/healthand-care-professionals/enga gement-and-participation-in-research/embedding-a-research-culture.htm] Accessed 10 Mar 2021.

46. National Institute for Health Research. NIHR's response to COVID-19: supporting the health and care system's response tothe pandemic 2020 [Available from: https://www.nihr.ac.uk/covid-19/. Accessed 10 Mar 2021.

47. Food and Drug Administration. Conduct of Clinical Trials of Medical Products During the COVID-19 Public HealthEmergency: Guidance for Industry, Investigators, and Institutional Review Boards. [Available from: https://www.fda.gov/media/136238. Accessed 27 Jan 2021.

48. European Medicines Agency. Guidance on the management of clinical trials during the COVID-10 (Coronavirus) pandemic.[Accessed February 04 2021] Version 4.

49. National Health Service (NHS) Health Research Authority. Making changes to a research study to manage the impact ofCOVID-19. [Accessed November 2020] Version 4.

50. Erridge S, Majeed A, Sodergren M. Virtual trials: looking beyond covid-19. British Medical Journal Opinion. 06 JULY 2020

51. Udeh-Momoh CT, de Jager-Loots CA, Price G, et al. Transition from physical to virtual visit format for a longitudinal brain aging study, in response to the COVID-19 pandemic. Operationalizing adaptive methods and challenges. Alzheimers Dement. 2020;6(1):e12055-e55. https://doi.org/10.1 002/trc2.12055.

\section{Publisher's Note}

Springer Nature remains neutral with regard to jurisdictional claims in published maps and institutional affiliations.

\section{Ready to submit your research? Choose BMC and benefit from:}

- fast, convenient online submission

- thorough peer review by experienced researchers in your field

- rapid publication on acceptance

- support for research data, including large and complex data types

- gold Open Access which fosters wider collaboration and increased citations

- maximum visibility for your research: over $100 \mathrm{M}$ website views per year

At BMC, research is always in progress.

Learn more biomedcentral.com/submissions 